\title{
Gorontalo
}

Journal of Public Health

Volume 2 - No. 2 - Oktober 2019

P-ISSN: 2614-5057, E-ISSN: 2614-5065

\section{Sejumlah Faktor yang Berhubungan dengan \\ Pemberian Vitamin A pada Balita}

\section{Factors Related with Giving of Vitamin A Toward Toddler}

\author{
Sunarti Hanapi ${ }^{*}$, Nuryani ${ }^{2}$, Rahmawaty Ahmad 1 \\ ${ }^{1}$ Ilmu Kesehatan Masyarakat, Fakultas Kesehatan Masyarakat, Universitas Gorontalo, \\ Gorontalo, Indonesia \\ *email: sunarti82hanapi@gmail.com \\ ${ }^{2}$ Ilmu Gizi, Fakultas Kesehatan Masyarakat, Universitas Gorontalo, \\ Gorontalo, Indonesia
}

\begin{abstract}
Based on Indonesian Basic Health Research 2018Vitamin A capsule coverage for children 6-59 months reached 53.1\%. Based on Department of Health Gorontalo district Vitamin A capsule coverage in work area of Asparaga community health center reached $80 \%$. The research aims at investigating association of giving vitamin A toward toddler. This research used observational analytic method with cross sectional study approach. This research was conducted in February until April with total of samples were 262 children 6-59 mount and respondents were toddler mother. The technique of collecting samples was using purposive sampling technique and the technique of data collection was using questionnaire. The technique of data analysis was chi square test. The findings reseacrh was found that the giving of vitamin A on toddler was $126(48,1 \%)$ and not giving vitamin $A$ was 136 (51,9\%) toddlers, low mothers knowledge 63,4\%, active cadre 28,2\%, active participation toddlers $5,0 \%$. Base on analysis bivariate indicated that sufficient knowledge of mothers $67,7 \%$ of the toddlers were given vitamin $A$ and chi square test showed knowledge of $p$ value $=0,000$, the role of active cadres $82,4 \%$ of the toddlers were given vitamin $A$ with $p$ value $=0,000$ and the activity of toddlers visiting community health center / Posyandu 100\% of the toddlers were given vitamin $A$ with $p$ value $=0,000$. It was concluded that the mothers knowledge factor, the role of cadres and the activity of toddlers visiting Community Health Center and Posyandu were related to the provision of viramin A in the toddlers. It was recommended for mothers of toddlers to explore more information regarding the importance of providing vitamin $A$ to toddlers, and to be active partisipation in Community Health Center / Posyandu activities.
\end{abstract}

Keywords; toddlers, activeness of visit, knowledge, role of cadres, vitamin A

\begin{abstract}
Abstrak
Berdasarkan hasil Riskesdas 2018 cakupan kapsul vitamin A pada anak 6-59 bulan mencapai 53,1\%. Berdasarkan data Dinas Kesehatan Kabupaten Gorontalo cakupan pemberian vitamin A di Wilayah Kerja Puskesmas Asparaga mencapai $80 \%$. Tujuan dalam penelitian ini untuk mengetahui sejumlah faktor yang berhubungan dengan pemberian vitamin A pada balita. Penelitian ini menggunakan metode observasional analitik dengan rancangan cross sectional study. Penelitian ini dilakukan pada Februari sampai April dengan jumlah sampel 262 balita umur 6-59 bulan dengan ibu balita sebagai responden. Pengambilan sampel dengan tekhnik purvosive sampling dan pengumpulan data dengan menggunakan kuesioner, analisis menggunaka chi square test. Hasil
\end{abstract}


penelitian didapatkan pemberian vitamin A pada balita sebanyak $126(48,1 \%)$ dan tidak diberikan vitamin A sebanyak 136 (51,9\%) balita, pengetahuan ibu kurang $63,4 \%$, keaktifan kader $28,2 \%$, keaktifan kunjungan balita 5,0\%. Berdasarkan hasil uji bivariat menunjukkan pengetahuan ibu cukup 67,7\% anak balita diberikan vitamin A chi square test menunjukkan pengetahuan $p$ value $=$ 0,000 , peran kader aktif $82,4 \%$ balita diberikan vitamin $\mathrm{A}$ dengan $p$ value $=$ 0,000 , dan keaktifan kunjungan balita ke Puskesmas / Posyandu 100\% balita diberikan vitamin A dengan $p$ value $=0,000$ berhubungan dengan pemberian vitamin A pada balita. Disimpulkan bahwa faktor pengetahuan ibu, peran kader dan keaktifan kunjungan balita ke Puskesmas dan Posyandu berhubungan dengan pemberian viramin A pada balita. Disarankan kepada ibu balita agar lebih menggali informasi terkait pentingnya pemberian vitamin A pada balita, serta aktif dalam kegiatan Puskesmas / Posyandu.

Kata kunci; balita, keaktifan kunjungan, pengetahuan, peran kader, vitamin A

\section{PENDAHULUAN}

Vitamin A adalah salah satu zat gizi penting yang larut dalam lemak, disimpan dalam hati, dan tidak dapat diproduksi oleh tubuh sehingga harus dipenuhi dari luar tubuh. Kekurangan Vitamin A (KVA) dapat menurunkan system kekebalan tubuh balita serta meningkatkan risiko kesakitan dan kematian. Kekurangan vitamin A juga merupakan penyebab utama kebutaan pada anak yang dapat dicegah (Kemenkes RI, 2015). Diperkirakan pada satu waktu sebanyak 3 juta anak-anak buta karena kekurangan vitamin A, dan sebanyak 20-40 juta menderita kekurangan vitamin A pada tingkat lebih ringan. Perbedaan angka kematian antara anak yang kekurangan dan tidak kekurangan vitamin A kurang lebih sebesar 30\% (Ellya, 2013).

Terdapat sejumlah faktor yang dapat mempengaruhi pemberian vitamin A pada balita. Tingkat pendidikan ibu mempengaruhi pengetahuan ibu dalam pemberian vitamin A kepada anaknya, karena dengan tingkat pendidikan yang cukup tinggi, maka daya serap ibu terhadap suatu informasi atau ilmu juga akan semakin mudah (Astuti,2013). Selain pengetahuan ibu, tingkat keaktifan kader juga dapat berpengaruh terhadap pemberian vitamin A pada balita. Peranan kader sangat penting karena kader bertanggung jawab dalam pelaksanaan program posyandu. Peran kader sangat penting untuk menurunkan tingkat kematian bayi dan balita, dan meningkatkan taraf kesehatan masyarakat, khususnya kesehatan ibu dan anak balita melalui peran kader dalam memberikan informasi dan memobilisasi masyarakat melalui promosi kesehatan (Gilmore B and McAuliffe, 2013; Hardiyanti, 2017). Kunjungan balita ke Posyandu juga dapat menjadi faktor pendukung pemberian vitamin A pada balita. Kunjungan balita ke Posyandu yang paling baik adalah teratur setiap bulan atau 12 kali per tahun. Kunjungan balita ke Posyandu adalah datangnya balita ke Posyandu untuk mendapatkan pelayanan kesehatan misalnya penimbangan, imunisasi, penyuluhan gizi dan lain sebagainya (Astuti, 2013).

Berdasarkan hasil Riskesdas 2018 bahwa cakupan kapsul vitamin A yang diterima dalam 12 bulan terakhir pada anak 6-59 bulan yang sudah sesuai standar mencapai 53,5\%. Sedangkan berdasarkan data Dinas Kesehatan Kabupaten Gorontalo tahun 2015-2018, dari 21 Puskesmas, masih ada beberapa puskesmas yang belum maksimal dalam hal pemberian vitamin A pada balita yang terendah yaitu wilayah kerja Puskesmas Asparaga Kecamatan Asparaga Kabupaten Gorontalo 76\% di tahun 2017 dan 80\% di tahun 2018 (Dikes Kabupaten Gorontalo, 2018).

Rendahnya cakupan pemberian vitamin A dapat mempengaruhi status kesehatan pada anak balita, sehingga penelitian ini bertujuan untuk 
mengetahui faktor-faktor yang berhubungan dengan pemberian vitamin A pada balita.

\section{METODE}

Jenis penelitian adalah observasional analitik dengan pendekatan cross sectional study. Penelitian ini dilakukan di wilayah kerja Puskesmas Asparaga Kabupaten Gorontalo. Waktu penelitian ini dilaksanakan pada Ferbruari hingga April 2019. Populasi dalam penelitian ini adalah seluruh balita yang ada di Kecamatan Asparaga sebanyak 823 balita, dengan sampel 262 responden. Sampel penelitian ini adalah balita, sementara responden penelitian adalah orang tua dan atau keluarga yang mengasuh balita. Penentuan subjek penelitian menggunakan rumus perhitungan sampel (Didik, 2013). Teknik sampling yang digunakan dalam penelitian ini yaitu purposive sampling, yang memenuhi kriteria inklusi yakni balita yang berada diwilayah kerja Puskesmas Asparaga dan bersedia menjadi responden.

Data dikumpulkan melalui wawancara menggunakan kuesioner. Pemberian vitamin A adalah apabila ibu membawa balita ke puskesmasa/pelayanan kesehatan untuk mendapatkan vitamin A atau yang langsung diberikan oleh kader dirumah - rumah ibu yang memiliki balita 6 - 59 bulan. Pemberian vitamin A pada anak dilakukan pada umur 6-11 bulan berupa kapsul vitamin A (warna biru) 100.000 SI, pada balita umur 12-59 bulan kapsul vitamin A (warna merah) 200.000 SI diberikan setiap bulan Februari dan Agustus setiap 6 bulan sekali (Kemenkes RI, 2015), dikategorikan diberikan vitamin A apabila responden membawa balita ke Puskesmas / Posyandu atau tempat pelayanan kesehatan untuk mendapatkan vitamin A dan memastikan vitamin A tersebut dikonsumsi balita, dikategorikan tidak diberikan vitamin A apabila responden tidak membawa balita ke Puskesmas / Posyandu atau ke tempat pelayanan kesehatan untuk mendapatkan vitamin A. Pengetahuan ibu adalah pengetahuan ibu balita mengenai manfaat pemberian vitamin A pada balita, dikategorikan pengetahuan cukup jika jawaban responden benar $\geq 50 \%$ dan kategori pengetahuan kurang jika jawaban responden $<50 \%$ (Astuti, 2013). Peran kader adalah kondisi dimana kader memberikan pelayanan yang baik, semua balita yang datang ke Posyandu harus mendapatkan vitamin A dan ibu mendapatkan edukasi terkait manfaat pemberian vitamin A pada balita (Onthonie et al., 2015). Dikategorikan peran kaderv aktif jika jawaban responden benar $\geq 50 \%$ dan kurang aktif jika jawaban responden < 50\%. Keaktifan balita mengunjungi adalah kunjungan balita ke Puskesmas / Posyandu, dikategorikan aktif jika kehadiran/kunjungan dalam setahun $\geq 8$ kali dalam satu tahun, sementara kategori kurang aktif jika kunjungan $<8$ kali (Astuti, 2013). Analisis data menggunakan analisis univariat dan bivariat. Uji statistik yang digunakan adalah chi square test dengan menggunakan aplikasi SPSS versi 16. Data yang telah diolah disajikan dalam bentuk table dan disertai dengan penjelasan.

\section{HASIL DAN PEMBAHASAN \\ Karakteristik Subjek Penelitian}

Karakteristik responden dalam penelitian ini ditunjukkan pada Tabel 1. Karakteristik berdasarkan kategori umur ibu, umur balita, jenis kelamin, dan pendidikan ibu. Karakteristik umur ibu paling banyak pada ketegori umur 22 26 tahun yakni sebanyak 41,7\%, sementara karakteristik pendidikan ibu paling banyak pada kategori tingkat pendidikan sekolah dasar (SD) yakni 60,7\%. Karakterisitk balita berdasarkan umur paling banyak pada kategori umur 16 25 bulan yakni 53,1\%, karateristik jenis kelamin 59,5\% laki - laki dan 40,5\% perempuan. 
Tabel 1. Karakteristik Respoden Ibu dan Balita pada Subjek Penelitian

\begin{tabular}{lcc}
\hline Karakteristik & \multicolumn{2}{c}{ Jumlah } \\
\cline { 2 - 3 }$\quad$ Responden & $\%$ & $\mathrm{n}$ \\
\hline Umur Ibu (tahun) & 50 & 19,1 \\
$17-21$ & 109 & 41,7 \\
$22-26$ & 86 & 32,9 \\
$27-31$ & 16 & 6,1 \\
$32-36$ & 1 & 0,4 \\
$37-41$ & & \\
Pendidikan Ibu & 24 & 9,2 \\
Tidak Tamat SD & 159 & 60,7 \\
SD & 40 & 15,3 \\
SMP & 34 & 13,0 \\
SMA & 5 & 1,9 \\
PT & & \\
Umur Balita (bulan) & 119 & 45,4 \\
$6-15$ & 139 & 53,1 \\
$16-25$ & 19 & 7,3 \\
$26-35$ & 3 & 1,1 \\
36-45 & 1 & 0,4 \\
$46-55$ & & \\
Jenis Kelamin & 156 & 59,5 \\
Laki-laki & 106 & 40,5 \\
Perempuan & 262 & 100 \\
\hline Total & & \\
\hline
\end{tabular}

\section{Hubungan Pengetahuan, Peran Kader dan Keaktifan Kunjungan Balita dengan Pemberian Vitamin A}

Analisis bivariat yang menilai hubungan antara pengetahuan, peran kader, dan keaktifan kunjungan balita ke puskesmas/posyandu ditunjukkan pada Tabel 2. Hasil penelitian menunjukkan secara keseluruhan balita yang tidak diberikan vitamina A $(51,9 \%)$ lebih besar dibandingkan dengan balita yang tidak diberikan vitamin A $(48,1 \%)$. Analisis variabel pengetahuan menunjukkan sebagian besar responden memiliki pengetahuan kurang yakni 63,4\%, analisis bivariat menunjukkan balita yang diberikan vitamin A dengan lebih tinggi dengan responden berpengetahuan cukup yakni 67,7\% dibandingkan dengan balita yang tidak diberikan vitamin $\mathrm{A}$, analisis chi square test diperoleh nilai $p$ value $=0,000$. Analisis variabel peran kader menunjukkan sebagian besar termasuk kategori kurang aktif yakni $71,3 \%$, analisis bivariat menunjukkan peran kader aktif lebih banyak pada kelompok balita yang diberikan vitamin A yakni $82,4 \%$ dibandingkan dengan balita yang tidak diberikan vitamin A yakni $17,6 \%$, hasil uji chi square test diperoleh nilai $p$ value $=0,000$. Analisis variabel kunjungan balita menunjukkan sebagian besar termasuk kurang aktif yakni $95,0 \%$, analisis bivariat menunjukkan balita 100\% yang aktif ke Posyandu mendapatkan vitamin $\mathrm{A}$, hasil uji chi square test diperoleh nilai $p$ value $=0,000$.

Analisis univariat menunjukkan balita yang tidak diberikan vitamin A yakni $51,9 \%$ lebih tinggi dibandingkan dengan balita yang diberikan vitamin yakni hanya $48,1 \%$. Cakupan vitamin A pada penelitian ini lebih rendah dibandingkan hasil penelitian Putri et al., (2017) yang mendapatkan bahwa persentase cakupan vitamin A balita $97,27 \%$. Hasil penelitian di Libya yang mendapatkan cakupan vitamin A pada balita 66\% (Abdulmalek \& Benkhaial, 2018). Demikian juga dengan hasil penelitian di Senegal yang mendapatkan cakupan pemberian vitamin A mencapai $98 \%$, hal ini disebabkan adanya kampanye suplementasi vitamin A (Horton et al., 2018). 
Tabel 2. Analisis Faktor yang Berhubungan dengan Pemberian Vitamin A pada Balita

\begin{tabular}{|c|c|c|c|c|c|c|c|}
\hline \multirow{4}{*}{ Variabel } & \multicolumn{6}{|c|}{$\begin{array}{l}\text { Pemberian Vitamin A Pada Balita } \\
\text { Total }\end{array}$} & \multirow{4}{*}{$p$ value } \\
\hline & \multirow{2}{*}{\multicolumn{2}{|c|}{ Diberikan }} & \multicolumn{2}{|c|}{ Tidak } & \multirow{3}{*}{$\mathrm{n}$} & \multirow{3}{*}{$\%$} & \\
\hline & & & Dib & rikan & & & \\
\hline & $\mathrm{n}$ & $\%$ & $\mathrm{n}$ & $\%$ & & & \\
\hline \multicolumn{8}{|l|}{ Pengetahuan } \\
\hline Cukup & 65 & 67,7 & 31 & 32,3 & 96 & 36,6 & 0,000 \\
\hline Kurang & 61 & 36,7 & 105 & 63,3 & 166 & 63,4 & \\
\hline \multicolumn{8}{|l|}{ Peran Kader } \\
\hline Aktif & 61 & 82,4 & 13 & 17,6 & 74 & 28,2 & 0,000 \\
\hline Kurang Aktif & 65 & 34,6 & 123 & 65,4 & 188 & 71,8 & \\
\hline \multicolumn{8}{|c|}{ Keaktifan Kunjugan Balita } \\
\hline Aktif & 13 & 100 & 0 & 0 & 13 & 5,0 & 0,000 \\
\hline Kurang Aktif & 113 & 45,4 & 136 & 54,6 & 249 & 95,0 & \\
\hline Total & 126 & 48,1 & 136 & 51,9 & 262 & 100 & \\
\hline
\end{tabular}

Hasil penelitian menunjukkan bahwa terdapat hubungan yang signifikan antara pengetahuan dengan pemberian vitamin A pada balita ( $p$ value $=0,000$ ) Hasil penelitian sejalan dengan penelitian yang dilakukan oleh Fithriyana (2016) yang menunjukkan bahwa terdapat hubungan antara pengetahuan ibu dengan pemberian vitamin A pada balita di Desa Kuantan Sako. Sebanyak 63,4\% responden memiliki pengetahuan yang kurang tentang vitamin $\mathrm{A}$, hal ini hampir sama dengan hasil penelitian Abdulmalek \& Benkhaial (2018) yang menunjukkan $60 \%$ responden ibu balita memiliki pengetahuan kurang tentang vitamin A dan terdapat hubungan antara pengetahuan ibu dengan pemberian vitamin A pada balita ( $p$ value < 0,001). Penelitian di Desa Hegarmanah Jatinagor menunjukkan tinnginya pengetahuan ibu terkait suplementasi vitamin A, lebih dari separuh ibu yang pengetahuannya baik tentang supelemtansi vitamin A mendapatkan suplementasi vitamin A untuk anak balitanya (Putri et al., 2017).

Pengetahuan kesehatan akan berpengaruh kepada perilaku sebagai hasil jangka menengah dari pendidikan kesehatan. Pengetahuan adalah segala sesuatu yang telah diketahui, adapun cara mengetahui sesuatu dapat dilakukan dengan cara mendengar, melihat, merasa dan sebagainya. Semakin tinggi tingkat pengetahuan semakin baik pula upaya ibu untuk patuh dalam memberikan vitamin A pada balita (Putri, 2014). Sebagian besar responden memiliki penetahuan kurang yang dapat disebabkan karena sebagian besar ibu balita berpendidikan rendah. Sebagaimana yang diketahui bahwa pendidikan berkaitan erat dengan pengetahuan, pengetahuan yang kurang akan mengakibatkan ibu tidak terdorong untuk memberikan vitamin pada saat yang tepat. Asupan vitamin balita akan cenderung tidak tercukupi jika seorang ibu tidak terlalu memperhatikannya. Faktor lainnya yang dapat mempengaruhi pengetahuan ibu yang berdampak pada rendahkan pemberian vitamin A pada balita adalah akses informasi yang cenderung sulit dijangkau oleh keluarga balita, mengingat ada beberapa desa yang lokasinya jauh dari Puskesmas/Posyandu sudah termasuk pedalaman dan tidak ada jaringan, sulit untuk ditempuh akibat jalan yang rusak, ada yang harus menyeberangi sungai sehingga informasi cenderung tidak didapatkan.

Hasil analisis data mengunakan uji statistic chi-square menunjukkan nilai $\mathrm{p}=$ 0,000 , sehingga peran kader ada hubungan yang signifikan dengan pemberian vitamin A pada balita. Hasil penelitian ini sejalan dengan Onthonie (2015) dalam penelitiannya membuktikan bahwa ada hubungan antara peran serta kader 
dengan pemberian vitamin A pada balita di wilayah kerja Puskesmas Manganitu Kabupaten Kepulauan Sangihe. Hasil penelitian menunjukkan bahwa peran kader yang aktif sebanyak $82,4 \%$ balita diberikan vitamin A. Peranan kader sangat penting karena kader bertanggung jawab dalam pelaksanaan program posyandu. Peran kader merupakan salah satu upaya pemerintah dalam memberdayakan masyarakat untuk menurunkan tingkat kematian bayi dan balita, dan meningkatkan taraf kesehatan masyarakat, khususnya kesehatan ibu dan anak balita di banyak negara melalui peran kader dalam memberikan informasi dan memobilisasi masyarakat melalui promosi kesehatan (Gilmore B and McAuliffe, 2013; Hardiyanti, 2017).

Meskipun demikian peran kader kurang aktif $(71,8 \%)$ lebih besar dibandingkan peran kader yang tergolong aktif $(28,2 \%)$. Bila kader tidak aktif, maka pelaksanaan posyandu juga akan menjadi tidak lancar dan akibatnya status gizi bayi dan balita (bawah lima tahun tidak dapat dideteksi secara dini dengan jelas. Berdasarkan wawancara yang dilakukan bersama responden salah satu penyebab kurang aktifnya peran kader dalam penelitian ini yaitu bahwa kader sering berganti-ganti orang hal ini terkait dengan motivasi kader rendah dan juga upah kader yang tidak seberapa sehingga menyebabkan kader menjadi jenuh dalam kegiatan posyandu yang mempengaruhi minat ibu membawa balita untuk mendapatkan vitamin A di puskesmas/posyandu.

Analisis statistik menggunakan uji chi square test diperoleh nilai $p$ value $=$ 0,000, yang menunjukkan terdapat hubungan antara peran kader dengan pemberian vitamin A pada balita. Penelitian ini tidak sejalan dengan penelitian yang dilakukan oleh Astuti (2013) yang menunjukkan bahwa tidak ada hubungan antara keaktifan kunjungan balita dengan pemberikan vitamin A pada balita di Posyandu Daya Makmur Sleman dengan nilai $p$ value $=0.725$. Pada penelitian ini keaktifan kunjungan balita ada hubungan dengan pemberian vitamin A pada balita, keaktifan kunjungan balita 100\% diberikan vitamin A. Meskipun demikian analisis univariat menunjukkan sebagian besar balita masih tergolong kurang aktif berkunjuing ke Posyandu yakni 95,5\% lebih tinggi dibandingkan dengan balita yang aktif ke Posyandu yakni hanya 5\% .

Kunjungan balita ke posyandu adalah datangnya balita ke posyandu untuk mendapatkan pelayanan kesehatan misalnya penimbangan, imunisasi, penyuluhan gizi dan lain sebagainya. Keaktifan kunjungan balita datang ke posyandu merupakan salah satu pencapaian pemenuhan status gizi balita dengan berbagai kejadian malnutrisi seperti balita pendek (stunting), kurus (wasting) dan gemuk (overweight)(Noeralim, 2017). Rendahnya keaktifan balita ke Posyandu pada penelitian ini disebabkan banyak ibu balita yang berpendidikan rendah sehingga membuat ibu balita tidak terdorong untuk membawa anaknya ke Puskesmas secara rutin. Terdapat perbedaan cakupan vitamin A yang signifikan berdasarkan latar belakang pendidikan orang tua balita (Semba et al., 2008). Selain itu, lokasi penelitian merupakan salah satu daerah daerah pelosok dengan jarak tempuh ke pelayanan kesehatan membutuhkan waktu yang lama sehingga mempengaruhi minat ibu untuk membawa balita untuk mendapatkan vitamin A. Akses menuju Puskesmas/Posyandu yang jauh dan sulit ditempuh sehingga apabila ada pertemuan seperti penyuluhan, masyarakat cenderung tidak menghadiri pertemuan tersebut, sehingga informasi yang diberikan ketika penyuluhan tidak tersampaikan sepenuhnya terutama terkait pemantaun pertumbuhan dan perkembangan balita yang bisa dipantau melalui keaktifan kunjungan balita minimal dua belas kali dalam setahun. 


\section{PENUTUP}

Berdasarkan hasil penelitian dapat disimpulkan bahwa terdapat hubungan yang signifikan antara pengetahuan ibu dengan pemberian vitamin A yakni balita yang diberikan vitamin A lebih banyak dari ibu yang memiliki pengetahuan cukup, terdapat hubungan antara pemberian vitamin A pada balita dengan peran kader yakni balita yang diberikan vitamin A lebih banyak pada peran kader yang aktif, terdapat hubungan antara pemberian vitamin A dengan keaktifan kunjungan balita ke Posyandu yakni semua balita yang aktif berkungjung ke Posyandu diberikan vitamin A.

Disarankan kepada ibu-ibu yang memiliki anak balita agar selalu aktif dalam kegiatan Posyandu sehingga dapat memperoleh banyak pengetahuan, dengan mengikuti penyuluhan tetang pentingnya pemberian vitamin A atau gizi bagi balita. Kepada kader Posyandu agar lebih mengoptimalkan keaktifan dalam kegiatan Posyandu serta pemerintah Daerah kiranya dapat memberikan bimbingan tekhnis dan motivasi kepada kader Posyandu terkait perannya yang sangat penting dalam pemantauan permasalahan gizi dan kesehatan pada anak balita.

\section{DAFTAR PUSTAKA}

Abdulmalek LJ \& Benkhaial. 2018. Knowledge, Attitude and Practice of Parents Regarding Vitamin A Supplementation to Children in Benhazi, Libya. Ibnosina Journal of Medicine and Biomedical Sciences. 10(5): $174-177$.

Astuti EP. 2013. Faktor-Faktor yang Mempengaruhi Pemberian Vitamin A pada Balita Di Posyandu Dayu Makmur Sleman. (Skripsi). Stikes Jenderal Achmad Yani. Yogyakarta.

Didik B. 2003. Populasi, Sampling dan Besar Sampel. Pusdatin-Kemenkes RI. Jakarta.

Dinkes Kabupaten Gorontalo. 2018. Data Cakupan Pemberian Vitamin A Pada Balita. Gorontalo. Dinas Kesehatan Kabupaten Gorontalo.

Ellya. 2013. Gizi Dalam Kesehatan Reproduksi. Jakarta. Trans Info Media.

Fithriyana R. 2016. Hubungan Pengetahuan Ibu tentang Vitamin A dengan Pemberian Vitamin A pada Balita di Desa Kuantan Sako Tahun 2016. Jurnal Doppler Universitas Pahlawan Tuangku Tambusai. 2(1): 50 - 58.

Gilmore B and McAuliffe E. 2013. Effectiveness of community health workers delivering preventive interventions for maternal and child health in lowand middle-income countries: a systematic review. BMC Public Health. 13; 847.

Hardiyanti P. 2017. Peran Kader terhadap Peningkatan Gizi Balita Di Desa Banyuraden Sleman Yogyakarta. (Naskah Publikasi). Muhammadiyah Surakarta. Yogyakarta.

Horton S, Blum LS, Diouf M, Ndiaye B, Ndoye F, Niang K, Greig A. 2018. Delivering Vitamin A Supplements to Children Aged 6-59 Months: Comparing Delivery through Campaigns and through Routine Health Services in Senegal. Current Developments in Nutrition. 2(4): 1-10.

Kemenkes RI. (2015). Profil Kesehatan Republik Indonesia 2015. Jakarta. Kementerian Kesehatan Republik Indonesia.

Noeralim DN. 2017. Faktor-Faktor yang Berhubungan dengan Keaktifan Kunjungan Ibu Balita Ke Posyandu Desa Watuwau Kecamatan Lage Kabupaten Poso. (Naskah Publikasi). Universitas Muhammadiyah Palu. Palu.

Onthonie $\mathrm{H}$, Ismanto $\mathrm{Y}$, Onibala $\mathrm{F}$, Studi $\mathrm{P}$, Keperawatan I, Kedokteran F, Samratulangi U. 2015. Hubungan Peran serta Kader Posyandu dengan Status Gizi Balita Di Wilayah Kerja Puskesmas Manganitu Kepulauan Singihe. Journal Keperawatan. 3(2): $1-8$. 
Putri ED. 2014. Hubungan Tingkat Pengetahuan Ibu dengan Upaya Kepatuhan Pemberian Vitamin A pada Balita Di Puskesmas Wirobrajan Yogyakarta. (Naskah Publikasi). Sekolah Tinggi Ilmu Kesehatan 'Aisyiyah Yogyakarta. Yogyakarta.

Putri NAH, Isriati, Djais JTB. 2017. Coverage of Vitamin A Supplementation among Under-Five Children in Hegarmanah Village, Jatinangor in August 2014. Althea Medical Journal. 4(2): 197 - 2013.

Semba RD, de Pee S, Sun K, Bloem MW, Raju VK. 2008. Coverage of the national vitamin A supplementation program in Ethiopia. $J$ Trop Pediatr. 54 (2): $141-144$. 